\title{
Gendered (in)visibility in digital media contexts
}

\author{
Claudia Wilhelm, University of Vienna, Department of Communication, Austria \\ claudia.wilhelm@univie.ac.at
}

\begin{abstract}
In digital media environments, gendered inequalities can be observed on the level of representation and participation in online discussions and digital communities as well as regarding the prevalence of gender norms in self-presentations, and power relations in social interactions. The \#MeToo debate exemplifies how gendered inequalities become visible in social media but also reveals the increasing hostility against women online. Drawing on the concept of digital visibility and informed by theoretical perspectives on gendered digital visibility from gender and feminist research and media and communication studies, the article reviews current research and identifies three distinct processes that characterize gendered digital visibility: (1) replication, (2) reinforcement, and (3) resilience. In doing so, the article proposes a taxonomy of research on gendered digital visibility. Findings highlight the ambivalence of women's participation in online discussions as well as the replication and reinforcement of gender norms through digital technology. Moreover, interrelatedness of these processes and implications for future research are discussed.
\end{abstract}

\section{Keywords}

gender, gender stereotypes, digital media, social media, social networks, (digital) visibility, invisibility, \#MeToo

\section{Introduction}

The \#MeToo campaign is one of the most prominent examples of a feminist movement that has spread worldwide. Discussions on social media drew the attention of mass media and the public to women experiencing sexual abuse and harassment (Tambe, 2018). At the same time, the case \#MeToo also shows that this great attention was accompanied by hostility and trolling in response to digital feminist activism (Mendes, Ringrose, \& Keller, 2018). Being publicly visible on social media platforms or in digital news environments not only exposes individuals and social groups to direct responses of potential target groups (e.g., peers, the scientific community, politicians) but also to the public at large. Not only feminist activists, but also women journalists and scholars working on controversial topics experience harassment when they make themselves publicly visible on social media platforms (e.g., Stahel \& Schoen, 2019; Veletsianos, Houlden, Hodson, \& Gosse, 2018). By being agentic, i.e., speaking out in the public and defending their positions, these wom- en violate prescriptive gender stereotypes. Being attacked for this behavior is called a backlash effect (Rudman \& Glick, 2012).

Drawing on the concept of digital visibility (Thompson, 2005), the article analyzes gendered inequalities regarding digital visibility. Therefore, it reviews literature on the role of gender in digital media environments, focusing on social media and women's online participation as these contexts provide distinct examples of gendered visibility (Herring \& Stoerger, 2014). It considers gender and feminist concepts and media and communication theories to identify drivers and inhibitors of women's digital visibility. The literature review reveals that gendered visibility in digital media contexts can be explained by three different processes that derive from the interplay of gender and digital technology: (1) replication of offline standards, e.g., the representation of women in online discussions (Herring \& Stoerger, 2014), (2) reinforcement, e.g., anonymity and invisibility in digital media environments foster harassment (Suler, 2004), and (3) resilience, e.g., the diffusion of social movements (Henry, 2009) increases the 
digital visibility of women and gender issues. These patterns serve as a taxonomy of research on gendered digital visibility and are illustrated using the example of the (online) feminist movement \#MeToo. This movement can be traced back to the "MeToo" workshops for survivors of sexual violence by the African American women's rights activist Tarana Burke in 2006 (Tambe, 2018). The phrase "MeToo" was then adapted in the respective Twitter hashtag created by the actress Alyssa Milano in October 2017. In their tweets, Milano and other women denounced sexual abuse in the movie industry and raised public and mass media attention (Manikonda, Beigi, Liu, \& Kambhampati, 2018; Mendes et al., 2018). It became a globally visible movement as millions of women worldwide shared their personal experiences on social media (Rodino-Colocino, 2018).

Finally, implications for future empirical investigations of the three different patterns of gendered visibility are suggested. The term gender is not restricted to birth-assigned gender categories as it encompasses multiple facets of self-categorization, i.e., people's current gender identity, perceived self-relevant social expectations associated with one's self-categorization, gender performance as well as group-related societal evaluations (Hyde et al., 2019). It is important to note that the current analysis focuses on the visibility of women in digital media environments. Yet, it does not cover research on other genders, e.g., the visibility of non-binary and transgender people (e.g., Miller, 2019).

Before reviewing current literature on women's digital visibility, the next section introduces the concept of digital visibility and briefly outlines theoretical assumptions of gender and feminist research as well as media and communication studies that are relevant to the analysis of the relationship between visibility and gender.

\section{Theoretical approaches on gendered digital visibility}

Visibility in digital communication contexts means that perceptibility is separated from temporal, spatial and sensory limitations due to digitization (Thompson, 2005). These new perceptual conditions involve new forms of action and interaction between groups and individuals in order to struggle for their visibility in terms of representation, norms of interaction and power relations (Tenenboim-Weinblatt, 2013; Thompson, 2005). Besides race, class, religion, ethnic origin, ability and age, gender is deemed to be one relevant category to describe inequalities in digital visibility comprising the following sub-dimensions (Thompson, 2005): (1) The visibility of actors and groups addresses the representation and participation of all genders in digital media environments. (2) The visibility of gender norms applies to the gender-stereotyping of self-presentations and behaviors in social interactions online. (3) The visibility of power relations refers to gendered inequalities regarding the control of privacy as well as harassment and abuse in digital media environments.

To explain gendered digital visibility with respect to these sub-dimensions, one can refer to both gender and feminist communication research. Whereas gender communication scholars primarily focus on how gender representation and norms in media content and production affect individuals, feminist communication scholarship aims at a structural social change toward gender equality (Mendes \& Carter, 2008). Following the first line of research that originates from social psychological gender research, women's representation in digital media and their participation and communication styles are guided by societal gender role perceptions. As proposed by social role theory (Wood \& Eagly, 2012), gendered role perceptions in society are informed by gender stereotypes that derive from a gender-specific division of labor. Moreover, social-cognitive theory of gender development (Bussey \& Bandura, 1999) states that conforming to gender roles is part of a learning process in which individuals are rewarded when fulfilling gender role expectations and are punished if they do not. These theories support the idea that individuals internalize hierarchical gender relations that are reflected in 
gendered media representations and portrayals. Moreover, backlash theory (Rudman \& Glick, 2012) argues that violating gender norms can lead to social sanctions and punishment. Women are punished when they violate prescriptive gender stereotypes that define how they should be (e.g., warm and caring). They are also sanctioned when confirming to proscriptive gender stereotypes that define how they should not be (e.g., dominant and forceful; Prentice \& Carranza, 2002). In addition, taking a social constructionist perspective, concepts such as doing gender (West \& Zimmerman, 1987) and gender performativity (Butler, 1990) highlight the notion of gender as a recurring act that guides interactions and interpretations, establishing binary conceptualizations of opposing gender stereotypes. These approaches are inspired by Goffman's (1979) gender display framework considering gender as a collective negotiation through interactions (Baker \&Walsh, 2018). In sum, gender communication research mainly addresses individual level effects of gendered inequalities in media and communication contexts (Mendes \& Carter, 2008; Thiele, 2015) and tends to rely on binary conceptions of gender, although partially acknowledging the performative act of doing gender. Communication research representing the gender perspective investigates how the relationship between digital technology (e.g., platform characteristics) and gender norms affects self-presentations in social media (Baker \&Walsh, 2018; Bivens, 2017; Butkowski, Dixon, Weeks, \& Smith, 2020). Moreover, following the tradition of gender representation studies in media and communication research (Thiele, 2015), gender differences in political online participation are examined (Vochocova, Stetka, \& Mazak, 2016). Further studies that can be assigned to this line of research analyze how ideological orientation and social characteristics induce backlash effects against women in digital communication contexts (Wilhelm \& Joeckel, 2019) and how women professionals deal with online harassment and abuse (Chen et al., 2020; Sobiraj, 2018; Stahel \& Schoen, 2019; Veletsianos et al. 2018).
In contrast to gender communication research, the research interest of feminist communication scholars is closely linked to political movements such as feminist activism (Mendes \& Carter, 2008). Critical and feminist scholars characterize social media as a neoliberal postfeminist environment that promotes a hegemonic gender construction (Banet-Weiser, 2015). Being aware of ongoing inequalities, women adopt a neoliberal economic imperative and visibly demonstrate their self in accordance to the market (Toffoletti \& Thorpe, 2018). In contrast, digital feminism argues that digital media can make gender inequalities visible to the public at large and enables new forms of discourse about gender and sexism (e.g., hashtagfeminism; Baer, 2016). Moreover, feminist activism benefits from enhanced possibilities of self-synchronization of latent groups (Shirky, 2008) to take collective action in social media environments as it reduces the costs of coordination, i.e., bringing people together that are only loosely connected. The downsides of digital activism are captured by the concept of digital labor that emphasizes the safety and emotional work performed by feminist researchers (Arcy, 2016). Engagement in feminist digital activism is immaterial, unpaid work and has been considered a new digital and social form of labor (Gleeson, 2016). From this perspective, digital labor is assumed to reify problematic gender constructions.

Aiming at structural social change, certain feminist movements such as Black feminism refer to intersectional inequalities. The concept of intersectionality stresses the role of interrelations between social categories of difference such as gender, religion, social class, race or age that should be considered when analyzing social inequalities (Crenshaw, 1991; Hughes, 2011). These intersections also apply to representation, participation and power relations in digital media environments (e.g., Gabriel, 2016; Massanari, 2017; Prieler \& Kohlbacher, 2017).

The feminist perspective on gendered digital visibility is represented by critical analyses of postfeminist gendered self-presentations in social media (Bruce, 
2016; Toffoletti \& Thorpe, 2018), research analyzing the potential and practice of digital feminist activism (Clark-Parsons, 2018; Gabriel, 2016; Jackson, 2018; Jackson, Bailey, \& Foucault Welles, 2018; Linabary, Corple, \& Cooky, 2019; Mendes et al., 2018; Myles, 2019; Pruchniewska, 2019; Turley \& Fisher, 2018) and studies uncovering the threats to feminist activism such as online harassment (Drakett, Rickett, Day, \& Milnes, 2018; Massanari, 2017; Vera-Gray, 2017) and abuse (Eckert, 2018; Mendes, Keller, \& Ringrose, 2019; Stubbs-Richardson, Rader, \& Cosby, 2018).

In addition, media and (computer-mediated) communication theories complement the gender and feminist perspective by emphasizing or specifying the role of digital technology within these processes. The online disinhibition effect (Suler, 2004) serves to explain norm violations such as hate speech, harassment and abuse (e.g., Chen et al., 2020). Social media attention economy (Van Dijk, 2013) is linked with neoliberal postfeminist perspectives (Banet-Weiser, 2015) to explain gendered self-presentation online (Toffoletti \& Thorpe, 2018). In addition, actor-network theory is applied to incorporate the influence of platform components (Latour, 2005) on gendered representations and participation in online spaces (Duguay, 2016; Massanari, 2017). Another line of research links gender perspectives with theories of the public sphere (Fraser, 1990; Noelle-Neumann, 1974; Habermas, 1962) and the role of social networks (Gabriel, 2016; Sobiraij, 2018).

\section{A taxonomy of published research: Replication, reinforcement, resilience}

In order to identify drivers and inhibitors of gendered digital visibility, the literature review focuses on contemporary research investigating prevalence, standards and norms of women's digital visibility. The current review incorporates research on the three sub-dimensions of digital visibility outlined above, i.e., gendered representation and participation, gender norms and gendered power relations. For this purpose, it considers research articles published 2015-2019 in communication journals (e.g., Information, Communication, \& Society, Journal of Communication, New Media \& Society) as well as gender and feminist journals in social sciences (e.g., Feminism \& Psychology, Sex Roles) to cover different fields of gender and feminist communication research. To identify relevant literature, journal websites and literature databases were searched, using the terms gender, gender roles, gender stereotypes, \#MeToo, and backlash in combination with the terms digital media, social media, social networks, (digital) visibility / invisibility as key words. Although, \#MeToo was referred to as an example of digital visibility of feminist movements, the search was not restricted to this case, but extended to other phenomena of women's visibility in social media. Literature was reviewed with regard to theoretical background, i.e., gender and/or feminist scholarship as well as media and communication theories the studies refer to. Furthermore, it was examined whether the studies provide empirical evidence and / or assessment of women's digital visibility with respect to at least one of the three sub-dimensions, i.e., representation/participation, gender norms and power relations. The literature corpus was then systemized in accordance to these sub-dimensions of digital visibility. Analysis of literature revealed three patterns that describe how findings on women's digital visibility are framed: (1) replication, (2) reinforcement, and (3) resilience.

\subsection{Replication}

The replication pattern is guided by current observations of gender inequalities being reflected in digital technologies (Sobiraj, 2018). Replication tendencies can be observed on all three sub-dimensions of digital visibility as they concern the representation and participation of women in the public sphere, gender norms affecting self-presentation, identity and social interaction as well as inequalities in power relations fostering harassment and abusive behavior. 


\subsubsection{Representation and participation}

Women's underrepresentation in politics (Hughes, 2011) and in the public sphere at large is reflected in online political participation such that men are more visible as political actors than women (Vochocova et al., 2016). Relying on survey and content analysis data, Vochocova, Stetka, and Mazak (2016) show that men are more present and more active in political commenting on Facebook than women. Authors question the equalizing effect of social media environments on political participation stated in previous research (e.g., Gil de Zúñiga, Veenstra, Vraga, \& Shah, 2010). Furthermore, they point out that gender inequalities in online political participation mainly apply to more expressive, publicly visible participation, such as posting comments in public groups, and less to lower-threshold participation such as "liking" and sharing content or private communication.

On platforms such as Reddit, even higher degrees of homogeneity in terms of gender and race can be observed (Massanari, 2017): The dominance of White men in these communities promotes perceptions of women as objects or interlopers, which in turn reduces the attraction of these spaces for women and inhibits women's participation.

Further, research refers to the 'digital double bind', which entrenches structural inequalities in digital entrepreneurship (Duffy \& Pruchniewska, 2017). The digital double bind highlights the binary assignment of public and private to masculine and feminine respectively, which is also reflected in mainstream perceptions of gender on social networking sites such as Facebook (Bivens, 2017).

\subsubsection{Gender norms}

When users present themselves and interact with others in digital media environments, they widely conform to gender norms and stereotypes. Following Banet-Weiser's (2015) gendered "economies of visibility", Toffoletti and Thorpe (2018) claim that women's self-objectification of their bodies and visual appearance on Instagram fosters the persistence of gender stereotypes and conventional perceptions of gender and sexuality in digital media. From this perspective, neoliberal post-feminism (Banet-Weiser, 2015) linked with the attention economy in social media (Van Dijk, 2013) build the ground for a new currency in digital media contexts that is visibility. Post-feminist attitudes as well as the technology itself foster these replication tendencies. For instance, through app description and rating, content navigation, cross-platform connections and content generation tools, Instagram "guides users to create selfies congruent with the dominant discourses" (Duguay, 2016, p. 7). As such, in social media women are faced with gender norms of publicity and privacy that highlight the singularity of their appearance and expose them to public criticism and judgement whereas men's self-presentation and participation conforms to gender norms and therefore remains unquestioned (Salter, 2016). In sum, self-presentation is characterized by stereotypical cues amplified by technological affordances of social media, i.e., social media feedback options that serve as popularity cues (Butkowski et al., 2020). That is, posts of visual self-presentations that confirm hegemonic conceptions of gender are high ranked and gain high levels of acceptance (Baker \& Walsh, 2018). Similarly, \#MeToo has been criticized by feminists for overemphasizing celebrities and their self-representation due to the attention economy of commercial platforms, while at the same time marginalizing the experiences of colored women and low-income women (Clark-Parsons, 2019). The prevalence of gender norms in social media also touches the performance of gender identity. Although non-binary options are available, the binary gender norm is replicated through technology as software-user interactions still follow a binary structure (Bivens, 2017).

\subsubsection{Power relations}

A replication of traditional gendered power relations in online spaces is indicated by the emergence of sexual harassment and abuse, gender trolling, misogyny, and oth- 
er aggressive behaviors directed against women. In this context, researchers stress the reproduction of offline gender inequalities in social media (Sobiraj, 2018). That is, digital technologies reflect power dynamics established in face-to-face situations and other offline settings (e.g., representations in the mass media, workplace hierarchies, romantic relationships, harassment). Stubbs-Richardson, Rader, and Cosby (2018) report on the transfer of victim blaming in physical sexual assaults to incidents in social media contexts. In addition, men's intrusive practices that women experience in public physical spaces largely overlap with their practices in public online spaces (Vera-Gray, 2017). Hence, women may have similar intrusion experiences in public spaces online and offline. Accordingly, gender trolling is not a phenomenon that takes place exclusively in online spaces, but rather exemplifies the misogynistic nature of a society (Mantilla, 2015).

Online harassment is assumed to be an extension of oppressive power structures, i.e., systemic gender inequality in society (Rubin, 2016). Being visible in social media, feminist online activists as well as other women professionals face digital expressions of these power structures. Women bloggers' experiences of high levels of online harassment and abuse seem to be a result of the dominance of men in the public sphere that is transferred to online spaces (Eckert, 2018). Chen et al. (2020) conducted in-depth qualitative interviews with 75 female professional journalists from five different countries. Nearly all of them reported experiences of online harassment. Hence, for women, being agentic, e.g., confident and decisive, can induce backlash effects against them. This is particularly the case in leading positions in the workplace (Heilman, 2012; Leskinen, Rabelo, \& Cortina, 2015), but also in the media and academic context when publicly presenting their expertise or reporting on controversial issues (Chen et al., 2020; Dowell, 2013).

Backlash effects (Rudman \& Glick, 2012) can be interpreted as manifestations of gendered power relations. Thus, backlash effects against women in online environments illustrate the replication of offline power relations. Current online communication research shows that such backlash effects occur when women speak out in public or semi-public spaces, e.g., as journalists or scholars (e.g., Eckert, 2018; Veletsianos et al., 2018), and when they behave agentic or dominant in online discussions (Wilhelm \& Joeckel, 2019; Winkler, Halfmann, \& Freudenthaler, 2017). Wilhelm and Joeckel (2019) examined the effect of the author's gender on the acceptance of hate as well as counter speech comments. They found a backlash effect towards women commenters for both comment types: Comments by women were more likely to be flagged as harmful than comments by men. Winkler, Halfmann, and Freudenthaler (2017) investigated backlash effects in online discussions. Their research revealed a greater persuasive power of comments by men than by women. Women communicating in an agentic style appear to be less persuasive than men who communicate agenticly (see also Heilman, 2012).

In sum, studies assigned to the replication pattern mainly - although there are exceptions (Bivens, 2017) - follow binary gender conceptions by focusing on differences between women and men. This can be seen as a continuation of gender research conducted in traditional mass media contexts that analyzed binary differences in representation and the reproduction of gender norms and stereotypes in advertising, movies, and newspapers (Mendes \& Carter, 2008). This approach has been criticized for exaggerating differences (Hyde et al., 2019) and contributing to the persistence of binary gender stereotypes (Thiele, 2015).

\subsection{Reinforcement}

The reinforcement pattern describes developments where digital technology (enabling or inhibiting visibility) enhances persisting gender inequalities. Taking a critical and feminist poststructuralist perspective, Banet-Weiser and Miltner (2016) argue that the increased masculine hostility towards women online is the result of 
perceived changes in gendered power relations. Moreover, research revealing the replication of gender inequalities, as outlined in the previous section, also provides evidence of reinforcement tendencies.

\subsubsection{Representation and participation}

Increased political participation of women, e.g., feminist online activism, is inhibited due to a fear of backlash (Rudman \& Glick, 2012). That is, the perception of lacking emotional safety results in a stronger reluctance to make feminist views, opinions, and identities visible in public digital spaces (Jackson, 2018). Yet, feminist online activism involves safety and emotional work (Arcy, 2016).

Being sexually attacked online, women journalists who exhibit a more traditional gender role orientation reduce their engagement with the audience or even consider quitting journalism (Stahel \& Schoen, 2019). Moreover, against the background of hate speech and trolling, feminist online activism is described as "putting oneself out there 'in the line of fire'" (Mendes et al., 2018, p. 240). Such observations are indicative of a spiral of silence (NoelleNeumann, 1974), muting women's voices. The perception that one's opinion is in the minority leads individuals to fear social isolation and punishment if they speak out in public. Hence, they prefer to remain silent, particularly when salient moral issues are being discussed. For example, they avoid disclosing their positions on controversial issues (e.g., gay marriage, samesex adoption) as well as evidence of their sexual identity in mainstream social networks where they are connected to various social groups that are likely to disapprove their opinions and sexual identities (Fox \& Warber, 2015). As a consequence, women's self-censoring and averting controversy in social media fosters their underrepresentation in social media environments (Fox \& Warber, 2015; Jackson, 2018).

\subsubsection{Gender norms}

Relying on Goffman's (1979) gender display framework, Butkowski, Dixon, Weeks, and Smith (2020) find both replicating and reinforcing effects of social media feedback on gendered self-presentation through Instagram selfies, as gender display cues increase the number of likes and followers. The prevalence of postfeminist attitudes in social media hinders feminist activism online, as it promotes the acceptance of gender norms by emphasizing individuals' choice and self-determination in their conformity to traditional gender roles (Linabary et al., 2019).

\subsubsection{Power relations}

Drawing on sexual harassment and gender-related violence, previous research state that these incidents are facilitated by digital technologies (Sobiraj, 2018; Henry \& Powell, 2015; Vera-Gray, 2017). Applying actor-network theory (Latour, 2005), Massanari (2017) describes how Reddit's design, algorithm, and platform politics implicitly support these kinds of toxic digital cultures. In particular, based on long-term participant-observation and ethnographic study of the Reddit community, the author shows how Reddit's karma point system, aggregation of material across subreddits, ease of subreddit and user account creation, governance structure, and policies against offensive content support antifeminist and misogynistic activism. From this perspective, the platform reinforces the influence of antifeminist groups and contributes to an increase of gender inequalities.

Additionally, in social media women are faced with rape threats that are neutralized by elements of humor such as the use of emoticons (Drakett et al., 2018). In this way, and similar to using justifications and excuses in hate comments against other vulnerable social groups (Wilhelm, Joeckel, \& Ziegler, 2020), violence against women is downplayed, which is likely to increase the acceptance of such posts by a wider audience. Humor focusing on gender, race, sexuality, or sexual activities in the context of victim-blaming in social media can increase sexual violence issues (Stubbs-Richardson et al., 2018). The online disinhibition effect is also evident in gendered digital visibility, as one group's disinhibition online, e.g., posting hateful 
comments, causes another one's inhibition, e.g., refraining from online activism, (Suler, 2004). Engaging with the \#MeToo campaign, participants also experienced negative outcomes such as being subject to harassment on Twitter (Clark-Parsons, 2019).

More generally speaking, studies assigned to the reinforcement pattern address the role of digital media in fostering inequalities by facilitating harassment and gendered self-presentation (Mendes \& Carter, 2008). They also reveal the ambivalence between increased participation fostering empowerment and increased risks of backlash and emotional work as negative side effects. A further aspect of the reinforcement pattern is only marginally addressed, namely the overlap of social group affiliations affected by online discrimination and harassment, e.g., race and gender (Massanari, 2017).

\subsection{Resilience}

Resilience occurs when digital visibility serves to diminish gender inequalities or even leads to social change. Although it is argued above that platform characteristics can replicate and reinforce gender inequalities and binary gender norms (e.g., Butkowski et al., 2020; Linabary et al., 2019), these developments can also be the starting point of resistance. However, most studies that state tendencies of resilience are predominantly highlighting digital media's potential for enabling resilience (e.g., Jackson, 2018; Turley \& Fisher, 2018) rather than providing empirical evidence of the envisioned developments.

\subsubsection{Representation and participation}

Besides experiences of harassment and hostility, women's increased presence and activism in public online spaces as well as in male-dominated subcultures can build the ground for higher rates of participation. Women bloggers as being highly exposed to hate speech and harassment reported that they have become resistant to a certain degree when dealing with online abuse (Eckert, 2018). Hashtag activism, as enacted by participants in the \#MeToo movement, can increase the representa- tion of gender issues in social media channels (e.g., Myles, 2019). Openness and accessibility facilitate the emergence of new discourses on femininity as well as enable women to get into discourse and online spaces previously reserved for men (Bruce, 2016). Minority groups can establish an intersectional networked counter-public to fight misrepresentation and to get into mainstream media outlets (Jackson et al., 2018).

\subsubsection{Gender norms}

As argued above, participation and representation are prerequisites of gender diversity online, which in turn is likely to increase the acceptance of deviations from binary gender norms and can therefore initiate social change, e.g., decreasing women's objectification in the visual online economy (Salter, 2016). As a result, heightened acceptance can lead to higher levels of engagement. Sharing experiences of sexism and violence in social media groups or by using hashtags such as \#MeToo increases visibility of feminist activism and research (Vera-Gray, 2017).

The constitution of counter-publics not only supports social inclusion of different feminist groups but also helps them to create and perform gender identities that challenge binary gender norms (Jackson et al., 2018). By sharing impressions of their everyday life and promoting their cultural authenticity, Black British women bloggers create powerful counter-narratives to challenge negative representations of Black British female identity (Gabriel, 2016).

\subsubsection{Power relations}

The concept of the public sphere (Habermas, 1962), the idea of self-synchronization of latent groups (Shirky, 2008) and the creation of a counter public (Fraser, 1990) lead researchers to think about the potential of inclusivity, discursivity and solidarity with respect to marginalized groups in online spaces. Digital public spaces offer women possibilities of making their opinions and identities visible (Duguay, 2016; Mendes et al., 2018; Sobiraj, 2018). Feminist activists can initiate 
counter-discourses through subversion or denouncement of harmful social media content such as problematic memes (Drakett et al., 2018), sexism, and rape culture (Turley \& Fisher, 2018). Disclosure of gendered power relations, e.g., sharing experiences of sexual violence, can be seen as the first step to create new digital narratives on gender relations (Mendes et al., 2019). However, activism in online spaces such as \#MeToo can have both simultaneously liberating (sharing experiences and finding community) and oppressing effects (through re-victimization; Linabary et al., 2019). Further, scholars stress the role of digital technologies for solidarity and social change, e.g., providing networked publics that create a sense of belonging for young feminist activists and enabling social change via online petitions (Jackson, 2018; Lokot, 2018; Mendes et al., 2018). These studies also support the idea of the integrational capacity of social media for community building (e.g., Jackson, 2018).

Veletsianos et al. (2018) describe resistance as one coping strategy of women scholars to deal with online harassment. This strategy involves speaking out as well as the attempt to engage harassers into a dialogue. Besides resistance, self-protection is another coping strategy that aims at reducing harassers' power by increasing security settings or outsourcing reading of comments to others (Veletsianos et al., 2018). In a similar fashion, Pruchniewska (2019) refers to safe online spaces for women that are created by women to support each other in their real work life.

Overall, resilience studies highlight the empowering aspects of visibility in digital media. Increased digital visibility of women manifests itself in feminist online activism such as \#MeToo, which is seen as a part of a broader social movement. In line with deliberative norms of online participation, this body of research argues for inclusion and solidarity of all genders. At the same time, the critical feminist perspective stresses the vulnerability of feminist digital activism as well as the contrasting developments of feminism and antifeminism in online spaces (Linabary et al., 2019).

\section{Discussion and conclusion}

The \#MeToo campaign was initially started to empower women and other groups by making their experiences of sexual violence visible. Hence, in this article, the campaign was considered as indicative of the new conditions of gendered visibility in digital media environments. Although the hashtag enabled wide-spread participation, not all women benefited equally from this viral visibility, as "access to mainstream media representation continues to be structured by race, sexuality, and class" (Clark-Parsons, 2019, p. 12).

This article presented a literature review against the background of gendered inequalities in digital visibility. The analysis of research thereby followed three distinct processes of how gender representation, gender norms, and gendered power relations relate to digital technology, which are described as replication, reinforcement, and resilience. Table 1 summarizes the main results of this review. This research identified gender-related and / or technology-based mechanisms that force the replication of offline standards in gendered inequalities. The review showed that the dominance of (White) men in political online discussions and digital communities, as well as persisting gender-stereotypes held by women and men, inhibit women's stronger participation and representation. Furthermore, by prioritizing dominant gender perceptions and gender binarity, social media software reproduces normative gender conceptions. In addition, users themselves support these replication tendencies by conforming to traditional gender roles in online self-presentations and interactions. Hence, the persistence of gender norms in online spaces is a precondition of the conservation of gendered power structures, as phenomena like slut-shaming and victim-blaming, which occur online and offline, arise from highly gender-stereotyped attributions. 
Table 1: Processes of gendered visibility in digital media contexts

\begin{tabular}{llll}
\hline Dimensions of digital visibility & Replication & Reinforcement & Resilience \\
\hline Representation and & (White) male dominance in & Fear of backlash leads to & Creation of counter and \\
participation & digital spaces, e. g. political & avoidance of masculine digital & networked publics increases \\
& online communication, inhibits \\
participation & spaces eliciting & visibility, in particular, if they are \\
& spiral of silence processes & acknowledged by mainstream \\
& & media; e. g., hashtag activism as \\
enacted by \#MeToo
\end{tabular}

Visibility of gender norms

Power relations

\begin{abstract}
Social media platforms prioritize dominant discourses and gender binarity, gendered self-presentation and interaction patterns online; e.g. \#MeToo's overemphasis on celebrities' self-presentation at the cost of diversity and visibility of women of color

Persistence of gender norms as a precondition of, gender trolling, slut-shaming and victim blaming
\end{abstract}

Social media feedback supports post-feministic self-presentations in social media

Anonymity facilitates objectification and disinhibition; e.g. \#MeToo campaigners' experiences of harassment on Twitter
Visibility of counter-stereotypical gender identities fosters their normalization and social change; e. g., \#MeToo counters women's objectification and increases the visibility of feminist activism

Solidarity and empowerment of women through digital technology, e. g., feminist online activism such as \#MeToo, online petitions, creation of safe online spaces

Note: Examples in italics refer to the \#MeToo movement.

Additionally, it was shown that fear of backlash (e.g., social isolation) and the perception to belong to a minority can reinforce women's underrepresentation in online discussions and digital communities. Moreover, the combination of prevailing binary gender norms and digital media characteristics (social media feedback) is a driver of the reinforcement of gendered stereotyping, which is reflected in highly objectified self-presentations; although these self-objectifications are assumed to be freely chosen and to support women's independence.

Lastly, the analysis revealed processes of resilience that reduce gender inequalities online. Research findings indicate that issues of underrepresentation can only be solved by higher levels of participation and stronger engagement, even though it could be embarrassing and demanding (referred to as digital labor; Vera-Gray, 2017). Thus, as proposed by movements of digital activism, increased participation can be a strategy to invert spiral of silence processes. In a further step, counter-publics and counter-narratives can help to deconstruct gender stereotyping and to make gender diversity visible to a wider audience. Fem- inist groups and movements practicing online activism foster women's empowerment and benefit from openness and accessibility of online platforms. Beyond that, these spaces can also be used to create safe places that facilitate community building and reduce digital labor.

It is important to note the dynamic character and reciprocity of these patterns, i.e., replication may blend into reinforcement (e.g., self-objectification in social media) whereas reinforcement can also be a consequence of increased resilience (e.g., harassment of feminist online activists). Furthermore, offline resilience can be replicated online. For example, increased representation of women in politics is likely to increase their online visibility. Digital mediation (Kember \& Zylinska, 2012), i. e., the process of blurring boundaries between real life and online space, can be a useful concept to account for such tendencies.

The theoretical and methodological approach of this literature review is not without limitations. Acknowledging that the result of the strategy of selecting literature applied here is non-exhaustive, this procedure aimed at an informed selection of current research covering gender 
research and feminist scholarship as well as different dimensions of digital visibility. The current research focused on the explanation of gendered inequalities. The theoretical lens applied here might have led to an overestimation of (binary) gender gaps, differences, and their effects. However, reviewed research assigned to the resilience pattern may serve to balance the possible bias of this perspective. Including a feminist perspective also highlights the need for a critical, non-binary, and intersectional approach to research on digital visibility. The categorization and critical assessment of the studies that guided this literature review bear the risk of oversimplification as some studies can be assigned to more than one category. Further, it must be taken into account that the fields of gender and feminist communication studies often overlap (Mendes \& Carter, 2008). It is important to note that the focus on studies analyzing the digital visibility of women left aside other inequalities in digital visibility at the expense of e.g., non-binary and trans persons (e.g., Miller, 2019). Future studies can adopt the proposed taxonomy and apply it to research on other genders to overcome this deficiency. Moreover, the current analysis focused on gender as a relevant category of social difference, only partially accounting for relations to other social categories. Analyzing the intersections in digital visibility between gender and other social categories reveals the heterogeneity of women's online experiences (Prieler \& Kohlbacher, 2017; Pruchniewska, 2019). Moreover, the critical assessment of the \#MeToo debate (e.g., Trott, 2020) stresses the need for an intersectional perspective that goes beyond the scope of this article.

The taxonomy of research on different dimensions of digital visibility proposed in this article sheds light on the antecedents of inequalities, polarization, and social change in digital media environments that can be described as an interplay of technological affordances and social / gender norms. Applying this taxonomy to research on women's digital visibility is only a first step that should be complemented by investigating further gender categories (non-binary, trans) and their intersections with other social categorizations and characteristics (e.g., sexual orientation; Ferris \& Duguay, 2020). Further development of this approach can help to disentangle the causes and consequences of inequalities in digital visibility by identifying processes of replication, reinforcement, and resilience. Future studies should investigate how digital technology can be used to foster resilience and to facilitate social change. Furthermore, most of the studies in this review relied on qualitative interview data (e.g., Sobiraij, 2018) and content analyses (e.g., Drakett et al., 2018), but also innovative methods such as app walkthrough (Duguay, 2016) and longterm observation (Massanari, 2017) were applied. Innovative methods and qualitative research could be complemented by quantitative data on participation, gathered using computational methods. Further analyses on power relations in social media contexts could apply network-analysis techniques. Moreover, experimental designs could be useful to test causalities and interrelations between the visibility dimensions proposed in this article, e.g., to assess the effects of increased participation on the perception of gender norms online. Extending study results on gendered inequalities in digital visibility reviewed in this article, future research should make greater efforts to derive practical implications, i.e., what measures social media platforms, news organizations, and governments could and should take, to protect and increase the visibility of women and other social groups online (also see Veletsianos et al., 2018).

\section{References}

Arcy, J. (2016). Emotion work: Considering gender in digital labor. Feminist Media Studies, 16(2), 365-368. https://doi.org/10. 1080/14680777.2016.1138609.

Baer, H. (2016). Redoing feminism: Digital activism, body politics, and neoliberalism. Feminist Media Studies, 16(1), 17-34. https://doi.org/10.1080/14680777.2015.1 093070. 
Baker, A. S. \& Walsh, M. J. (2018). "Good Morning Fitfam": Top posts, hashtags and gender display on Instagram. New Media \& Society, 20(12), 4553-4570. https://doi. org/10.1177/1461444818777514.

Banet-Weiser, S. (2015). Media, markets, gender: Economies of visibility in a neoliberal moment. The Communication Review, 18(1), 53-70. https://doi.org/10.1080/1071 4421.2015.996398.

Banet-Weiser, S., \& Miltner, K. M. (2016). \#MasculinitySoFragile: Culture, structure, and networked misogyny. Feminist Media Studies, 16(1), 171-174. https://doi.org/10. 1080/14680777.2016.1120490.

Bivens, R. (2017). The gender binary will not be deprogrammed: Ten years of coding gender on Facebook. New Media \& Society, 19(6), 880-898. https://doi. org/10.1177/1461444815621527.

Bruce, T. (2016). New rules for new times: Sportswomen and media representation in the third wave. Sex Roles, 74(7 / 8), 361-376. https://doi.org/10.1007/s11199015-0497-6.

Bryce, J., \& Rutter, J. (2005). Gendered gaming in gendered space. In J. Raessens \& J. H. Goldstein (Eds.), Handbook of computer game studies (pp. 301-310). Cambridge: MIT Press.

Bussey, K., \& Bandura, A. (1999). Social cognitive theory of gender development and differentiation. Psychological Review, 106(4), 676-713. Retrieved from https://psycnet. apa.org/buy/1999-11924-002.

Butler, J. (1990). Gender trouble: Feminism and the subversion of identity. New York: Routledge.

Butkowski, C. P., Dixon, T. L., Weeks, K. R., \& Smith, M. A. (2020). Quantifying the feminine self(ie): Gender display and social media feedback in young women's Instagram selfies. New Media \& Society, 22(5), 817-837. https://doi. org/10.1177/1461444819871669.

Chen, G. M., Pain, P., Chen, V. Y., Mekelburg, M, Springer, N., \& Troger, F. (2020). "You really have to have a thick skin": A cross-cultural perspective on how online harassment influences female journalists. Journalism, 21(7), 877-895. https://doi. org/10.1177/1464884918768500.
Clark-Parsons, R. (2018). Building a digital Girl Army: The cultivation of feminist safe spaces online. New Media \& Society, 20(6), 2125-2144. https://doi. org/10.1177/1461444817731919.

Clark-Parsons, R. (2019). "I see you, I believe you, I stand with you": \#MeToo and the performance of networked feminist visibility. Feminist Media Studies. Advance online publication. https://doi.org/10.108 0/14680777.2019.1628797.

Crenshaw, K. (1991). Mapping the margins: Intersectionality, identity politics, and violence against women of color. Stanford Law Review, 43(6), 1241-1299.

Drakett, J., Rickett, B., Day, K., \& Milnes, K. (2018). Old jokes, new media - online sexism and constructions of gender in internet memes. Feminism \& Psychology, 28(1), 109-127. https://doi. org/10.1177/0959353517727560.

Dowell, B. (2013, January 21). Mary Beard suffers "truly vile" online abuse after Question Time. The Guardian. Retrieved from https://www.theguardian.com/ media/2013/jan/21/mary-beard-sufferstwitter-abuse.

Duffy, B. E., \& Pruchniewska, U. (2017). Gender and self-enterprise in the social media age: A digital double bind. Information, Communication \& Society, 20(6), 843-859. https://doi.org/10.1080/136911 8X.2017.1291703.

Duguay, S. (2016). Lesbian, gay, bisexual, trans, and queer visibility through selfies: Comparing platform mediators across Ruby Rose's Instagram and Vine presence. Social Media + Society, 2(2), 1-12. https://doi. org/10.1177/2056305116641975.

Eckert, S. (2018). Fighting for recognition: Online abuse of women bloggers in Germany, Switzerland, the United Kingdom, and the United States. New Media \& Society, 20(4), 1282-1302. https://doi. org/10.1177/1461444816688457.

Ferris, L., Duguay, S. (2020). Tinder's lesbian digital imaginary: Investigating (im) permeable boundaries of sexual identity on a popular dating app. New Media \& Society, 22(3), 489-506. https://doi. org/10.1177/1461444819864903.

Fox, J. \& Warber, K.M. (2015). Queer identity management and political self-expression 
on social networking sites: A co-cultural approach to the spiral of silence. Journal of Communication, 65(1), 79-100. https:// doi.org/10.1111/jcom.12137.

Fraser, N. (1990). Rethinking the public sphere: A contribution to the critique of actually existing democracy. Social Text, 25-26, 56-80. Retrieved from https://www.jstor. org/stable/466240.

Gabriel, D. (2016). Blogging while Black, British and female: a critical study on discursive activism. Information, Communication, \&Society, 19(11), 1622-1635. https:// doi.org/10.1080/1369118X.2016.1146784.

Gleeson, J. (2016). “(Not) working 9-5”:

The consequences of contemporary Australian-based online feminist campaigns as digital labour. Media International Australia, 161(1), 77-85. https://doi. org/10.1177/1329878X16664999.

Goffman, E. (1979). Gender Advertisements. New York: Harper \& Row.

Gil de Zúñiga, H., Veenstra, A., Vraga, E., \& Shah, D. (2010). Digital democracy: Reimagining pathways to political participation. Journal of Information Technology \& Politics, 7(1), 36-51. https://doi. org/10.1080/19331680903316742.

Habermas, J. (1962). Strukturwandel der Öffentlichkeit [The structural transformation of the public sphere]. Frankfurt: Suhrkamp.

Heilman, M. E. (2012). Gender stereotypes and workplace bias. Research in Organizational Behavior, 32, 113-135. https://doi. org/10.1037/a0036734.

Henry, S. (2009). Social deviance. Cambridge: Polity Press.

Henry, N. \& Powell, A. (2015). Embodied harms: Gender, shame and technology-facilitated sexual violence in cyberspace. Violence Against Women, 21(6), 758-779. https:// doi.org/10.1177/1077801215576581.

Herring, S. C., \& Stoerger, S. (2014). Gender and (a)nonymity in computer-mediated communication. In S. Ehrlich, M. Meyerhoff, J.xHolmes (Eds.), The handbook of language, gender, and sexuality $\left(2^{\text {nd }} e d\right.$., pp. 567-586). Chichester, West Sussex: Wiley Blackwell.

Hughes, M. M. (2011). Intersectionality, quotas, and minority women's political representation worldwide. American Political
Science Review, 105(3), 604-620. https:// doi.org/10.1017/S000305541100029.

Hyde, J. S., Bigler, R. S., Joel, D., Tate, C. C., \& van Anders, S. M. (2019). The future of sex and gender in psychology: Five challenges to the gender binary. American Psychologist, 74(2), 171-193. https://doi. org/10.1037/amp0000307.

Jackson, S. (2018). Young feminists, feminism and digital media. Feminism \& Psychology, 28(1), 32-49. https://doi. org/10.1177/0959353517716952.

Jackson, S. J., Bailey, M., \& Foucault Welles, B. (2018). \#GirlsLikeUs: Trans advocacy and community building online. New Media \& Society, 20(5), 1868-1888. https://doi. org/10.1177/1461444817709276.

Kember, S., \& Zylinska, J. (2012). Life after new media - mediation as a vital process. Cambridge, MA: MIT Press.

Latour, B. (2005). Reassembling the social: An introduction to actor-network-theory. Oxford: Oxford University Press.

Leskinen, E. A., Rabelo, V. C., \& Cortina, L. M. (2015). Gender stereotyping and harassment: A "catch-22" for women in the workplace. Psychology, Public Policy, and Law, 21(2), 192-204. https://doi.org/10.1037/ law0000040.

Linabary, J. R., Corple, D. J. \& Cooky, C. (2019). Feminist activism in digital space: Postfeminist contradictions in \#WhyIStayed. New Media \& Society. Advance online publication. https://doi. org/10.1177/1461444819884635.

Lokot, T. (2018). \#IAmNotAfraidToSayIt: Stories of sexual violence as everyday political speech on Facebook. Information, Communication, \& Society, 21(6), 802-817. https://doi.org/10.1080/136911 8X.2018.1430161.

Manikonda, L., Beigi, G., Liu, H., \& Kambhampati, S. (2018). Twitter for sparking a movement, reddit for sharing the moment: \#metoo through the lens of social media. arXiv preprint arXiv:1803.08022.

Mantilla, K. (2015). Gendertrolling: How misogyny went viral. Santa Barbara: Praeger Press.

Massanari, A. (2017). \#Gamergate and the Fappening: How Reddit's algorithm governance, and culture support toxic technocultures. New Media \& 
Society, 19(3), 329-346. https://doi. org/10.1177/1461444815608807.

Mendes, K., \& Carter, C. (2008). Feminist and gender media studies: A critical overview. Sociology Compass, 2(6), 1701-1718. https://doi.org/10.1111/ j.1751-9020.2008.00158.x.

Mendes, K., Keller, J. \& Ringrose, J. (2019). Digitized narratives of sexual violence: Making sexual violence felt and known through digital disclosures. New Media \& Society, 21(6), 1290-1310. https://doi. org/10.1177/1461444818820069.

Mendes, K., Ringrose, J., \& Keller, J. (2018). \#MeToo and the promise and pitfalls of challenging rape culture through digital feminist activism. European Journal of Women's Studies, 25(2), 236-246. https:// doi.org/10.1177/1350506818765318.

Miller, J. F. (2019). YouTube as a site of counternarratives to transnormativity. Journal of Homosexuality, 66(6), 815-837. https:// doi.org/10.1080/00918369.2018.1484629.

Myles, D. (2019). "Anne Goes rogue for abortion rights!": Hashtag feminism and the polyphonic nature of activist discourse. New Media \& Society, 21(2), 507-527. https:// doi.org/10.1177/1461444818800242.

Noelle-Neumann, E. (1974). The spiral of silence: A theory of public opinion. Journal of Communication, 24(2), 43-51. https:// doi.org/10.1111/j.1460-2466.1974. tb00367.x.

Prentice, D. A., \& Carranza, E. (2002). What women and men should be, shouldn't be, are allowed to be, and don't have to be: The content of prescriptive gender stereotypes. Psychology of Women Quarterly, 26, 269-281. https://doi.org/10.1111/14716402.t01-1-00066.

Prieler, M. \& Kohlbacher, F. (2017) Face-ism from an international perspective: Gendered self-presentation in online dating sites across seven countries. Sex Roles, 77(9/10), 606-614. https://doi. org/10.1007/s11199-017-0745-z.

Pruchniewska, U. (2019). "A group that's just women for women”: Feminist affordances of private Facebook groups for professionals. New Media \& Society, 21(6), 1362-1379. https://doi. org/10.1177/1461444818822490.
Rodino-Colocino, M. (2018). Me too, \#MeToo: Countering cruelty with empathy. Communication and Critical/Cultural Studies, 15(1), 96-100. https://doi.org/10.1080/ 14791420.2018 .1435083$.

Rubin, J. D. (2016) \#Gendertrolling: A (new) virtual iteration of everyday misogyny. Sex Roles, 74(5/6), 266-267. https://doi. org/10.1007/s11199-016-0577-2.

Rudman, L. A., \& Glick, P. (2012). The social psychology of gender: How power and intimacy shape gender relations. New York: Guilford Press.

Salter, M. (2016). Privates in the online public: Sex(ting) and reputation on social media. New Media \& Society, 18(11), 2723-2739. https://doi. org/10.1177/1461444815604133.

Shirky, C. (2008). Here comes everybody: The power of organizing without organizations. New York: Penguin Press.

Sobieraj, S. (2018). Bitch, slut, skank, cunt: Patterned resistance to women's visibility in digital publics. Information, Communication \& Society, 21(11), 1700-1714. https:// doi.org/10.1080/1369118X.2017.1348535.

Suler, J. (2004). The online disinhibition effect. Cyberpsychology \& Behavior, 7(3), 321-326. https://doi. org/10.1089/1094931041291295.

Stahel, L., \& Schoen, C. (2019). Female journalists under attack? Explaining gender differences in reactions to audiences' attacks. New Media \& Society. Advance online publication. https://doi. org/10.1177/1461444819885333.

Stubbs-Richardson, M., Rader, N. E., \& Cosby, A. G. (2018). Tweeting rape culture: Examining portrayals of victim blaming in discussions of sexual assault cases on Twitter. Feminism \& Psychology, 28(1), 90-108. https://doi. org/10.1177/0959353517715874.

Tambe, A. (2018). Reckoning with the silences of \#MeToo. Feminist Studies, 44(1), 197203. Retrieved from https://www.jstor.org/ stable/10.15767/feministstudies.44.1.0197.

Tenenboim-Weinblatt, K. (2013). The management of visibility: Media coverage of kidnapping and captivity cases around the world. Media, Culture \& 
Society, 35(7), 791-808. https://doi. org/10.1177/0163443713495075.

Thiele, M. (2015). Medien und Stereotype [Media and stereotypes]. Bielefeld: Transcript.

Thompson, J. B. (2005). The new visibility. Theory, Culture \& Society, 22(6), 31-51. https:// doi.org/10.1177/0263276405059413.

Toffoletti, K., \& Thorpe, H. (2018). Female athletes' self-representation on social media: A feminist analysis of neoliberal marketing strategies in "economies of visibility". Feminism \& Psychology, 28(1), 11-31. https:// doi.org/10.1177/0959353517726705.

Trott, V. (2020). Networked feminism: Counterpublics and the intersectional issues of \#MeToo. Feminist Media Studies. Advance online publication. https://doi.org/10.108 0/14680777.2020.1718176.

Turley, E., \& Fisher, J. (2018). Tweeting back while shouting back: Social media and feminist activism. Feminism \& Psychology, 28(1), 128-132. https://doi. org/10.1177/0959353517715875.

Van Dijk, J. (2013). The culture of connectivity: A critical history of social media. Oxford: Oxford University Press.

Veletsianos, G., Houlden, S., Hodson, J., \& Gosse, C. (2018). Women scholars' experiences with online harassment and abuse: Self-protection, resistance, acceptance, and self-blame. New Media \& Society, 20(12), 4689-4708. https://doi. org/10.1177/1461444818781324.

Vera-Gray, F. (2017). "Talk about a cunt with too much idle time": Trolling feminist research. Feminist Review, 115(1), 61-78. https://doi. org/10.1057/s41305-017-0038-y.

Vochocova, L., Stetka, V. \& Mazak, J. (2016). Good girls don't comment on politics?
Gendered character of online political participation in the Czech Republic. Information Communication and Society, 19(10), 1321-1339. https://doi.org/10.1080 / 1369118X.2015.1088881.

West, C., \& Zimmerman, D. H. (1987). Doing gender. Gender \& society, 1(2), 125-151. https://doi.org/10.1177/08912432870010 02002.

Wilhelm, C., \& Joeckel, S. (2019). Gendered morality and backlash effects in online discussions: An experimental study on how users respond to hate speech comments against women and sexual minorities. Sex Roles, 80(7), 381-392. https://doi. org/10.1007/s11199-018-0941-5.

Wilhelm, C., Joeckel, S., \& Ziegler, I. (2020). Reporting hate comments - investigating the effects of deviance characteristics, neutralization strategies and users' moral orientation. Communication Research, 47(6), 921-944. https://doi. org/10.1177/0093650219855330.

Winkler, J., Halfmann, A., \& Freudenthaler, R. (2017, May). Backlash effects in online discussions: Effects of gender and counter-stereotypical communication on persuasiveness and likeability. Paper presented at the 66th annual conference of the International Communication Association (ICA), San Diego, CA.

Wood, W., \& Eagly, A. H. (2012). Biosocial construction of sex differences and similarities in behavior. Advances in Experimental Social Psychology, 46, 55-123. https://doi. org/10.1016/B978-0-12-394281-4.00002-7. 